\title{
Orthodontic Surgical Treatment of Gummy Smile with Vertical Maxillary Excess
}

\author{
Dr. Suma $T^{1}$, Dr.Shashikumar H.C ${ }^{2}$, Dr.Lokesh N.K ${ }^{3}$, Dr. Siddarth Arya ${ }^{4}$, \\ Dr.Shwetha G.S $S^{5}$ \\ ${ }^{1}$ Reader, Department of Orthodontics \& Dentofacial Orthopedics, Rajarajeswari Dental College \& Hospital, Bangalore \\ ${ }^{2}$ Reader, Department of Orthodontics \& Dentofacial Orthopedics, Rajarajeswari Dental College \& Hospital, Bangalore \\ ${ }^{3}$ Reader, Department of Orthodontics \& Dentofacial Orthopedics, Rajarajeswari Dental College \& Hospital, Bangalore \\ ${ }^{4}$ Senior Lecturer, Department of Orthodontics \& Dentofacial Orthopedics, Rajarajeswari Dental College \& Hospital, \\ Bangalore \\ ${ }^{5}$ Professor, Department of Orthodontics \& Dentofacial Orthopedics, Rajarajeswari Dental College \& Hospital, Bangalore
}

\begin{abstract}
Clinical entity with several treatment options. Treatment of these cases requires extremely well-coordinated orthodontic and surgical treatment planning and execution. This is a case report of 30 year old female adult patient who presented with skeletal class II malocclusion with excessive vertical growth of maxilla. Vertical maxillary excess, thin alveolar troughs, proclined upper and lower anterior teeth, excessive curve of spee and excessive eruption of upper and lower incisors which led to decision of combination of orthodontic and surgical treatment. This case report represents twin jaw surgery. Le Fort I procedure with maxillary set back and sub apical osteotomy in mandibular arch. The presented technique was unique as it shortened the treatment time and resulted in good occlusion, function, and aesthetics.
\end{abstract}

Keywords: Gummy smile, vertical maxillary excess, orthognathic surgery

\section{Introduction}

Vertical maxillary excess, clinically recognizable facial morphology is manifested primarily by gummy smile, exposure of the maxillary teeth, with incompetent lips, increased length of lower facial, high mandibular plane angle. Cephalometric and occlusal analysis reveals Angle Class I malocclusion on a skeletal class II base. Such cases of skeletal Class II malocclusion usually require a combination of Orthodontic and Orthognathic surgical treatment. The treatment of severe dentofacial deformities in adult patients is challenging to both the orthodontic and oral surgeons. Treatment is difficult because of the skeletal and facial disharmony cessation of jaw growth and a tendency toward relapse after treatment. The surgical orthodontic correction of vertical maxillary excess via surgical superior repositioning of maxilla is generally acceptable treatment regime on the basis of skeletal stability and aesthetic soft tissue changes but results are not generally satisfactory. This article describes orthodontic surgical management of an adult patient with skeletal class II malocclusion caused by excessive vertical maxillary growth.

\section{Diagnosis}

A 32 year adult female patient with a chief complaint of protruding upper front teeth (fig 1) with an excessive exposure of gingiva. Initial examination reveals excess visibility of gingiva at rest and during smiling. Incompetent lip with gap of $12 \mathrm{~mm}$ suggesting of vertical maxillary excess. She had dolichocephalic, convex profile and posterior divergent and a high lip line with 9 to $10 \mathrm{~mm}$ of gingival visibility during smiling. Class I molar and class I canine with overjet of $4 \mathrm{~mm}$ and overbite of $5 \mathrm{~mm}$. Lower midline shifted to left side by $2 \mathrm{~mm}$ with mild lower anterior crowding( Table 1).
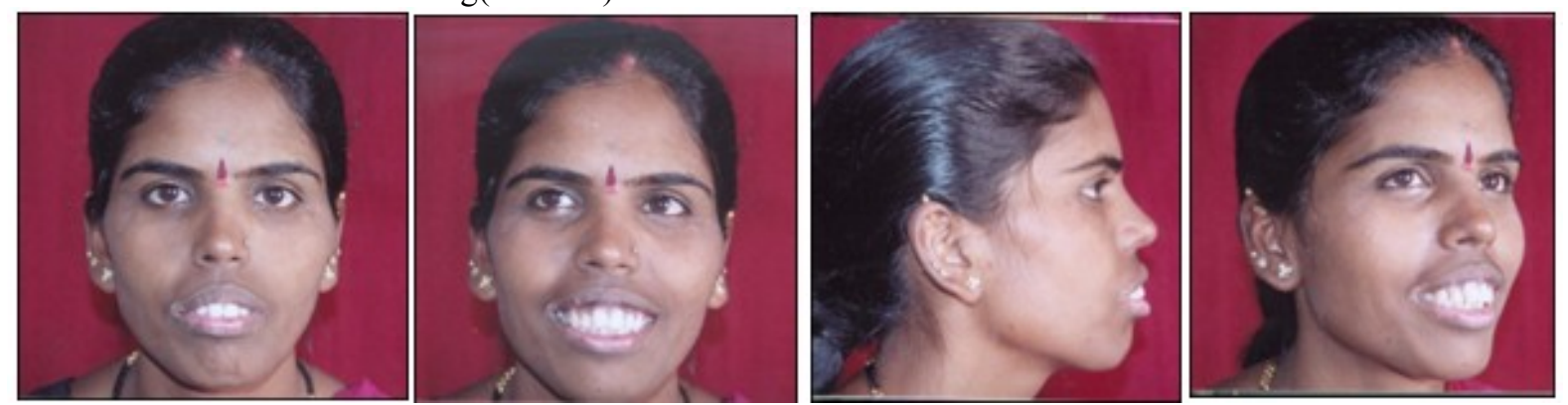

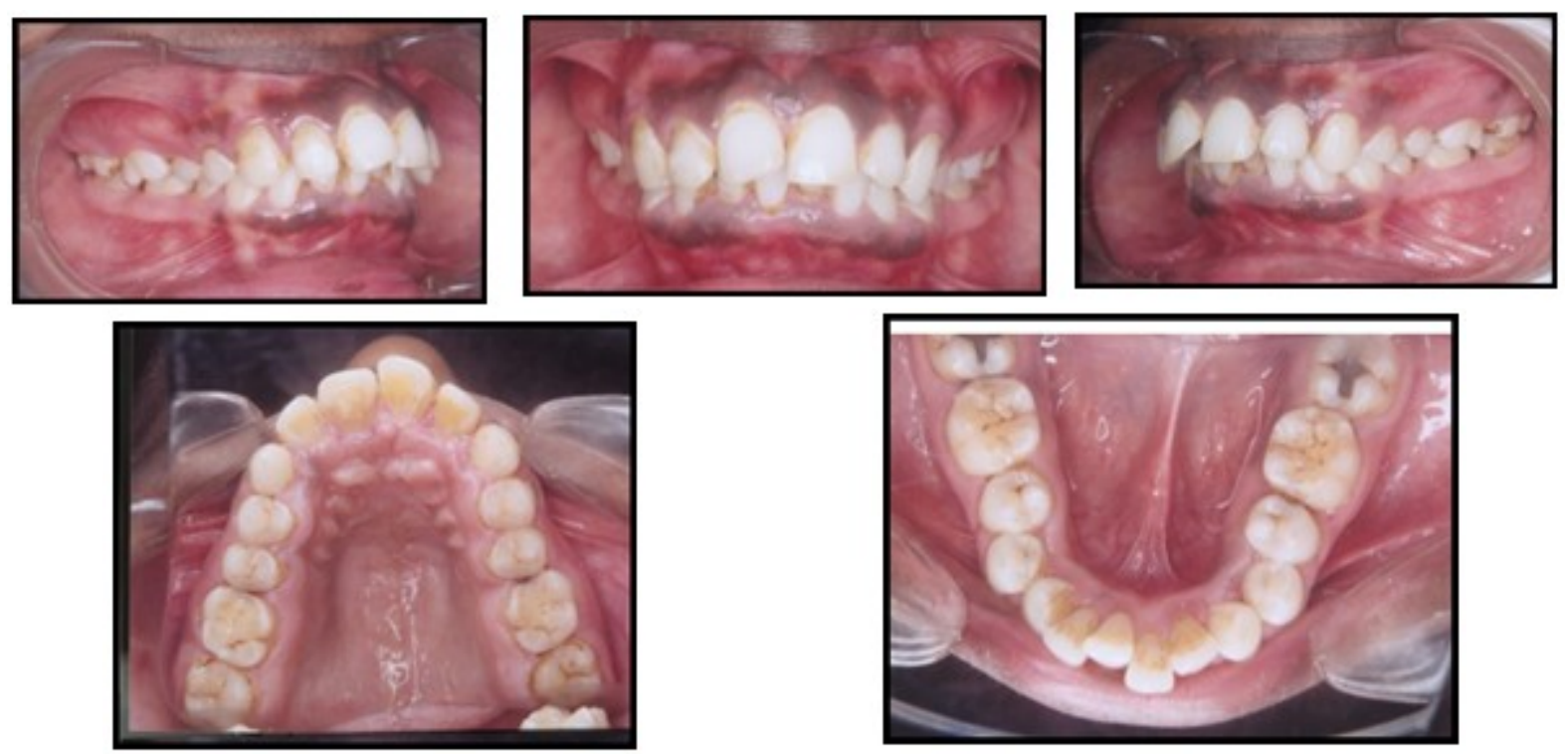

Fig 1: Pre Treatment Extraoral and Intra oral Photographs
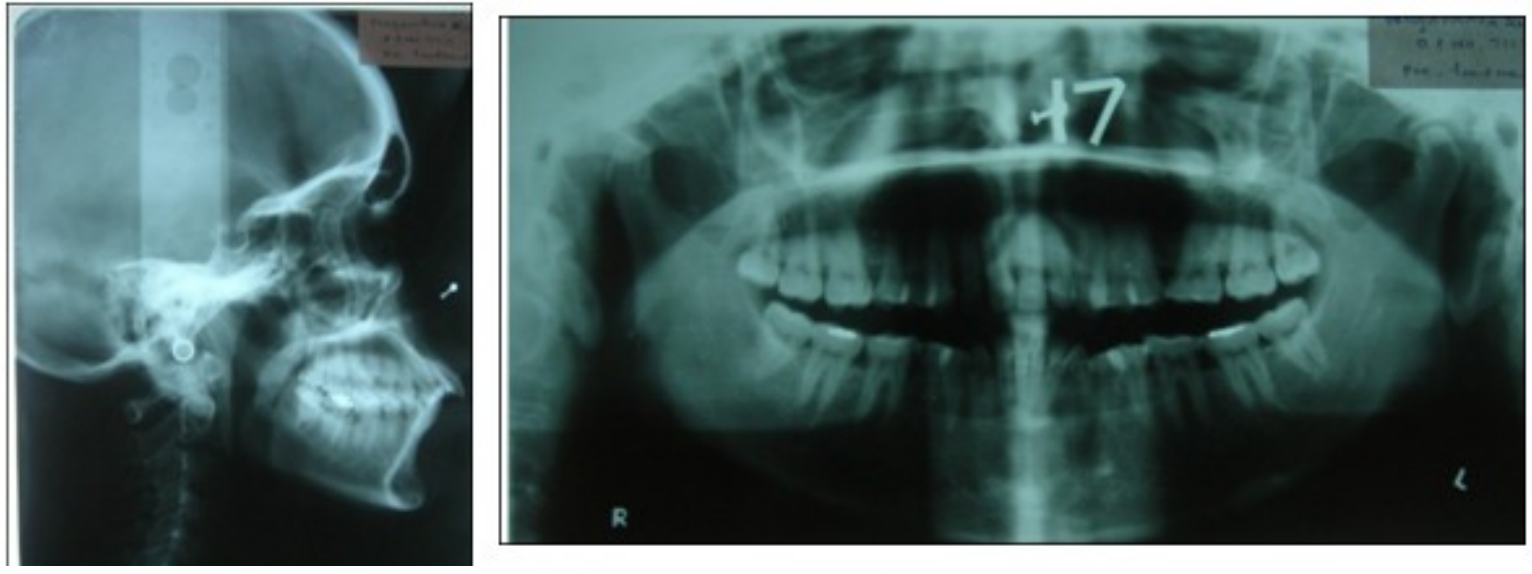

Fig 2: Pretreatment Radiographs

Cephalometric analysis revealed class II skeletal base with bimaxillary protrusion with ANB of $6^{0}$ patient present with average to vertical growth pattern with mandibular plane angle of $30^{\circ}$ and y-axis of $70^{\circ}$ (fig 2). The upper and lower anteriors were proclined according to Steiner's analysis. Excessive eruption of upper and lower incisors was noted according to Burstone analysis. This excessive eruption of incisors is seen in patients with vertical maxillary excess in order to partially compensate for the jaw rotation. The vertical maxillary excess, thin alveolar troughs, excessive curve of spee, proclined upper and lower anterior teeth, excessive eruption of upper and lower incisors warranted a surgical line of treatment (Table).

\section{Treatment Plan}

Treatment objectives were to improve the positioning of the maxillary arch with a reduction in the gingival exposure on smiling and at rest, to facilitate autorotation of the mandible, to match skeletal bases, to obtain a skeletal class I relation, to level and align the arches, to achieve an ideal overjet and overbite, correct lip incompetency and achieve an aesthetic profile. A surgical prediction was done and the treatment planned was, extraction of all four first premolars during surgery, mandibular subapical osteotomy to intrude the anterior segment by $5 \mathrm{~mm}$, maxillary superior repositioning of $5 \mathrm{~mm}$ by Le Fort I osteotomy along with anterior segmental osteotomy of the maxilla to setback the anterior alveolar segment by $6 \mathrm{~mm}$.

\section{Treatment progress}

First molars were banded and 0.022" preadjusted brackets (MBT Prescription) were bonded to the remaining teeth to the remaining teeth in both arches except first premolars in all quadrants since they had to be extracted during surgery. A continuous maxillary archwire of 0.016 " nickel titanium was inserted (Fig3). The archwire size in the maxilla was gradually increased until $0.019 \mathrm{X} 0.025$ " stainless steel wires were placed. This 
resulted in decrease in the maxillary anterior teeth proclination and deepening of the bite. Initial alignment wire was started with 0.016 " nickel titanium wire in the mandibular arch as well and gradually increased to $0.019 \mathrm{X} 0.025$ " stainless steel wire. Levelling of anterior segment was planned surgically by intruding the anterior segment because of the thin alveolar trough so as to avoid root resorption.
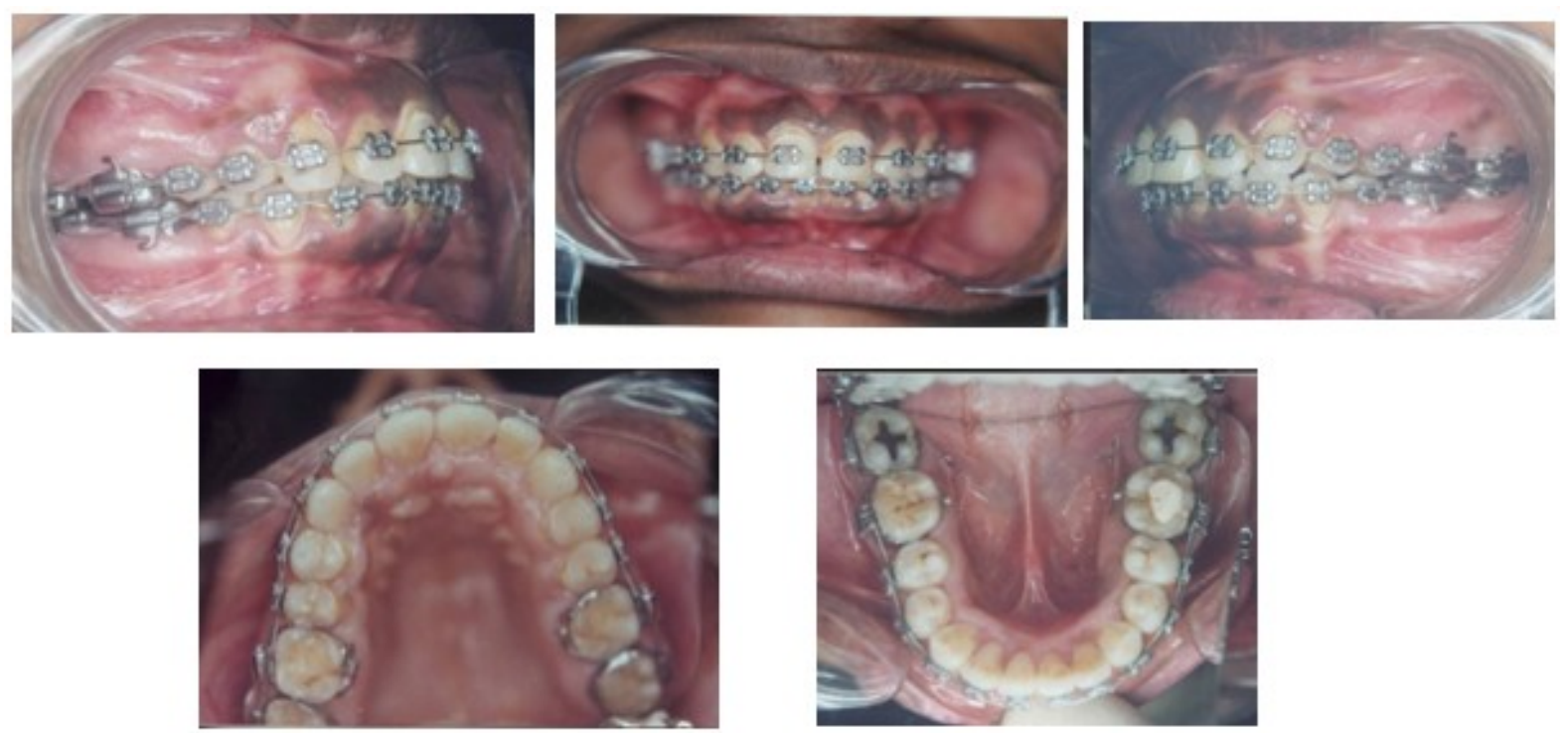

Fig 3 Intra oral photographs of Alignment \& Levelling

After 6 months of presurgical orthodontics (fig 4), surgery was performed. Two splints were fabricated with acrylic (Fig 5). Mandibular subapical osteotomy was carried out to intrude the anterior segment by $5 \mathrm{~mm}$, this was followed by Le Forte I osteotomy to superiorly reposition the maxilla by $5 \mathrm{~mm}$ and anterior segmental osteotomy of the maxilla to setback the anterior alveolar segment by $6 \mathrm{~mm}$. the maxilla was positioned superiorly so as to achieve 2 to $3 \mathrm{~mm}$ of maxillary incisor exposure with the upper lip at rest. Surgeries were performed without any complications and the correction was maintained by rigid fixation. After completion of the post-surgical finishing and detailing, the appliance was debonded. Total treatment duration was 2 years.
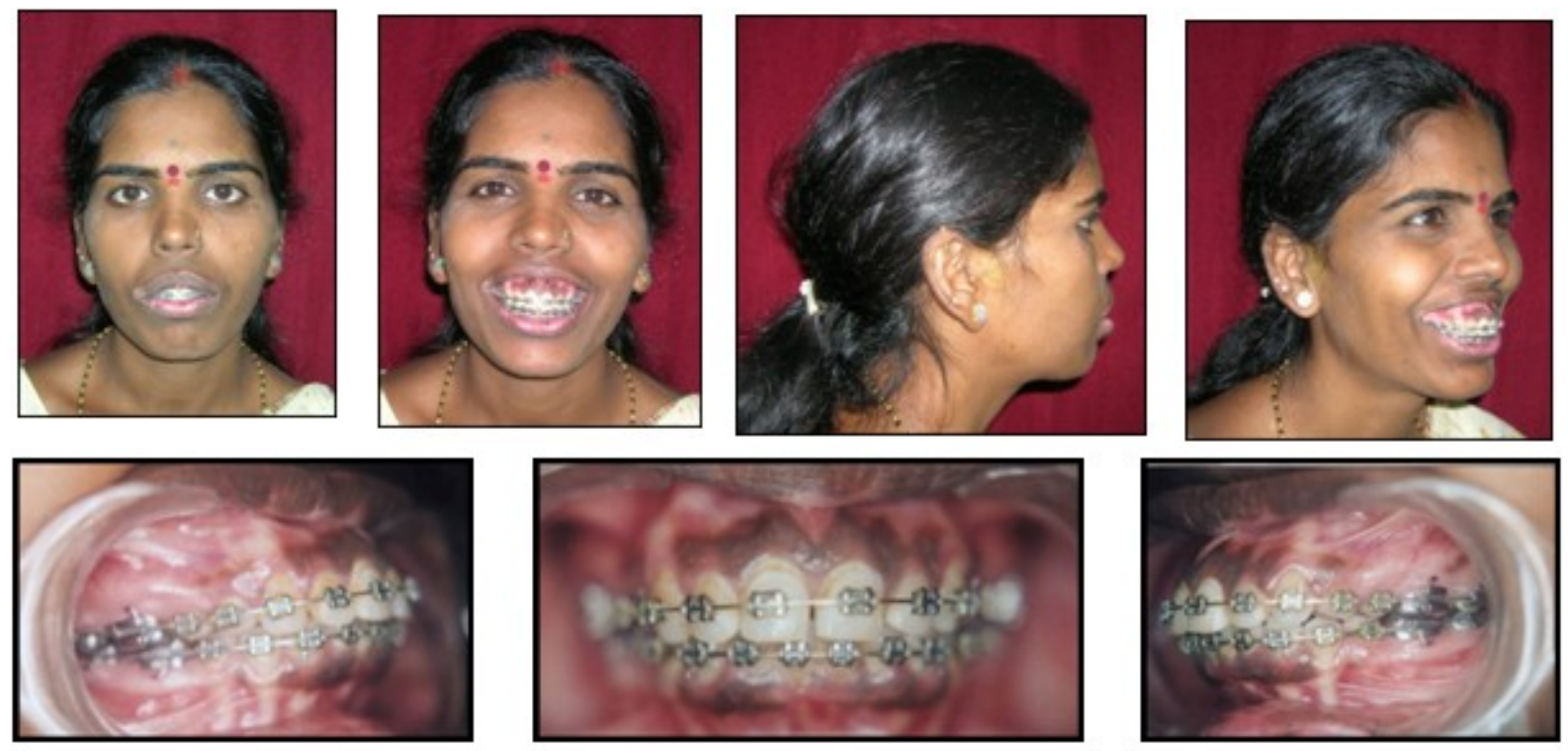

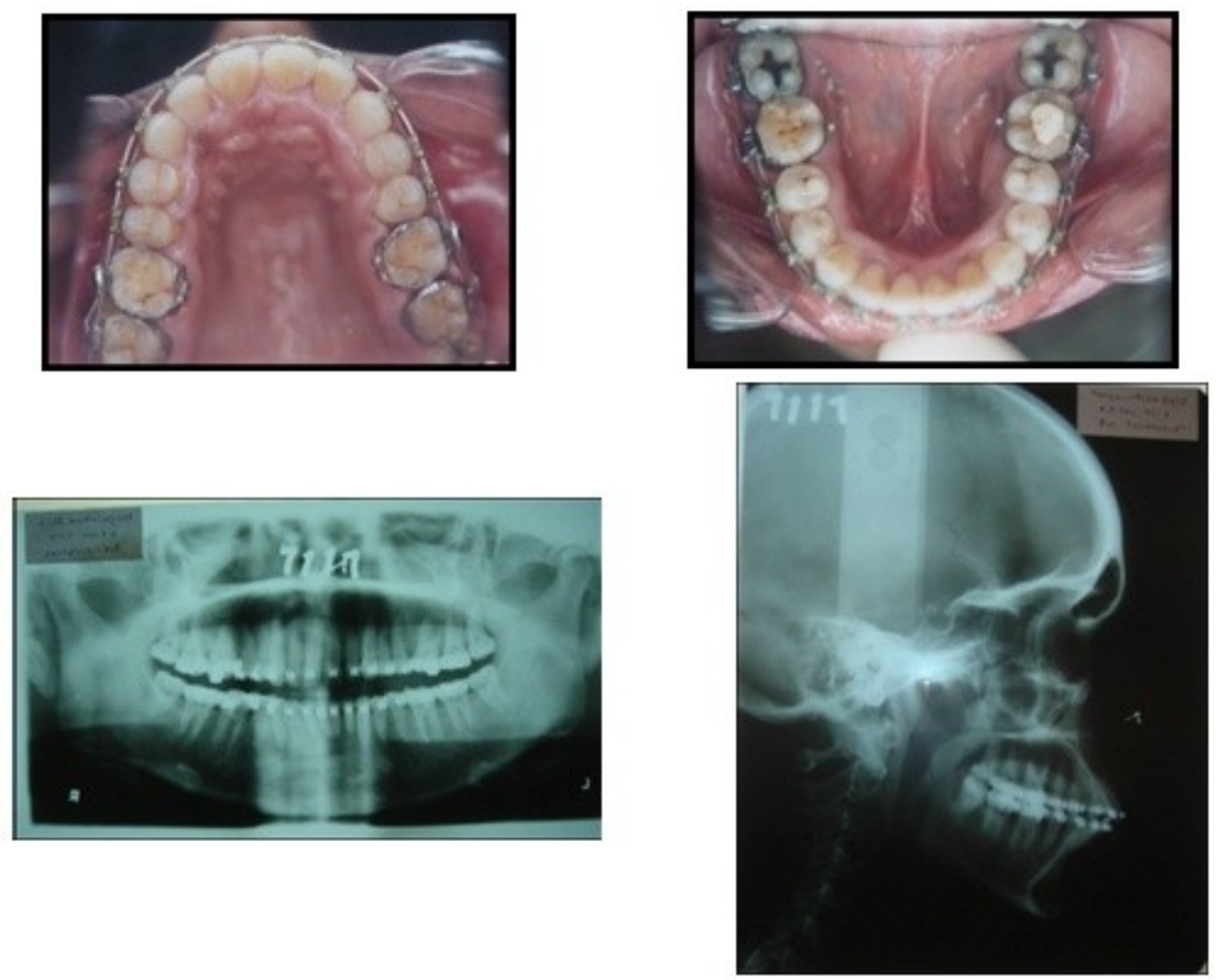

Fig 4: Presurgical Intraoral and extraoral photographs and radiographs
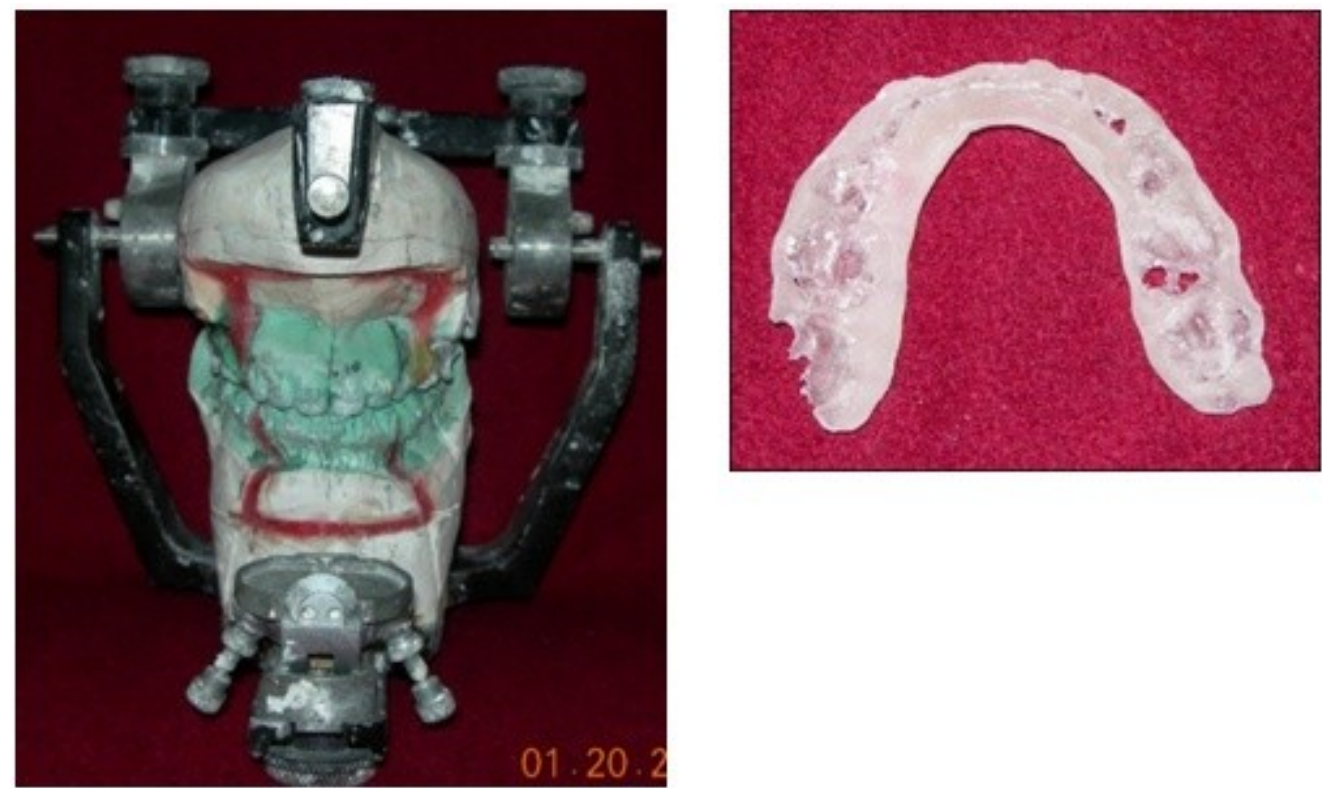

Fig 5: Mock Surgery and Surgical splints

\section{Results}

After completion of post-surgical orthodontics, a demonstrated facial symmetry with proportional facial thirds, a balanced maxillomandibular relationship, an aesthetic smile line and good lip positioning. Treatment produced Skeletal class I relation (Fig 6).

Superimposition of the pre-treatment and post-surgical cephalometric tracing indicated the amount of setback of the maxillary anterior segment and intrusion of the mandibular anterior segment (Fig 7). It also demonstrated the amount of superior repositioning of the maxilla along with the autorotation of the mandible. 

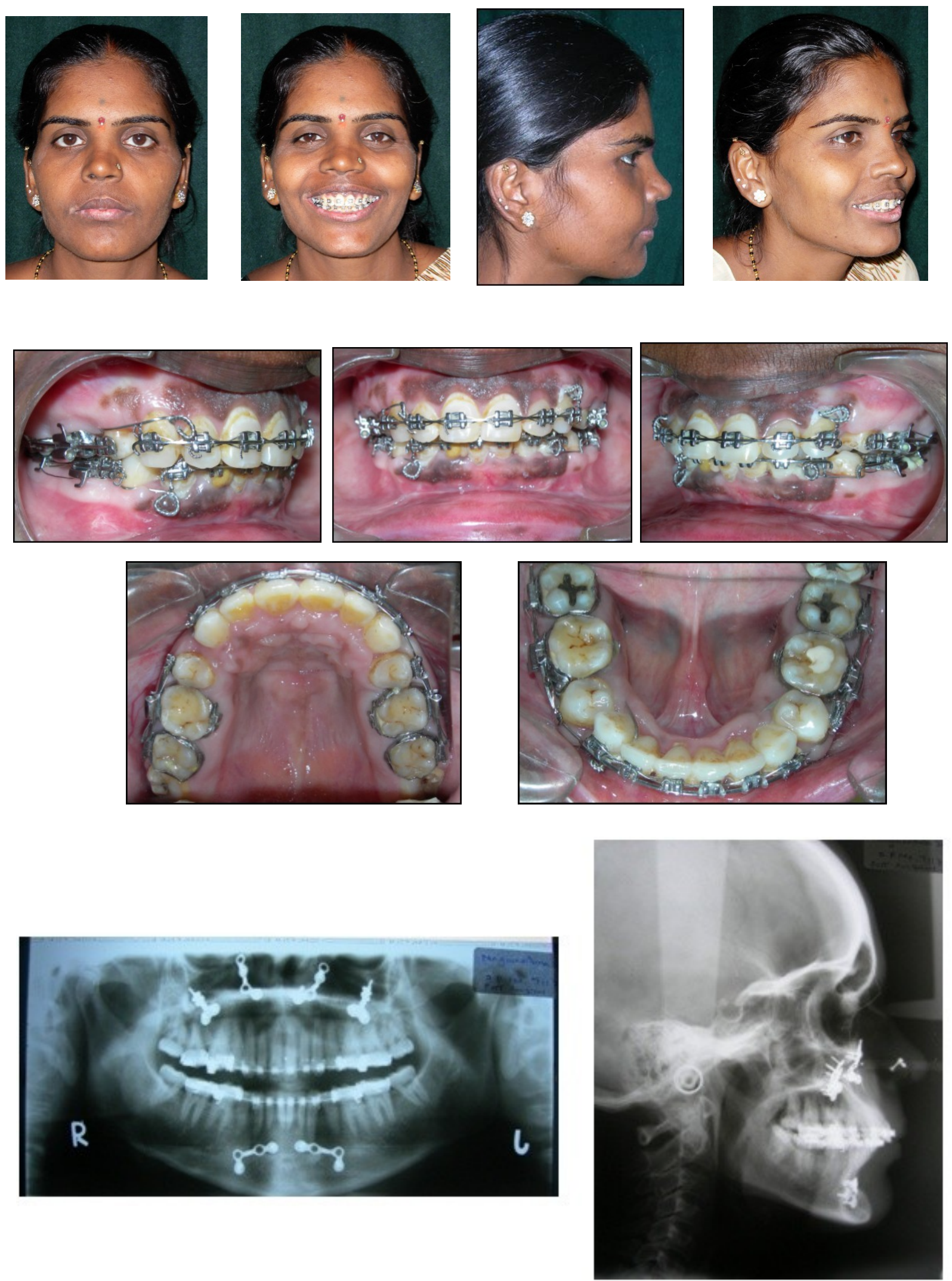

Fig 6: Post-Surgical Intraoral and ExtraoralPhotograps and radiographs 


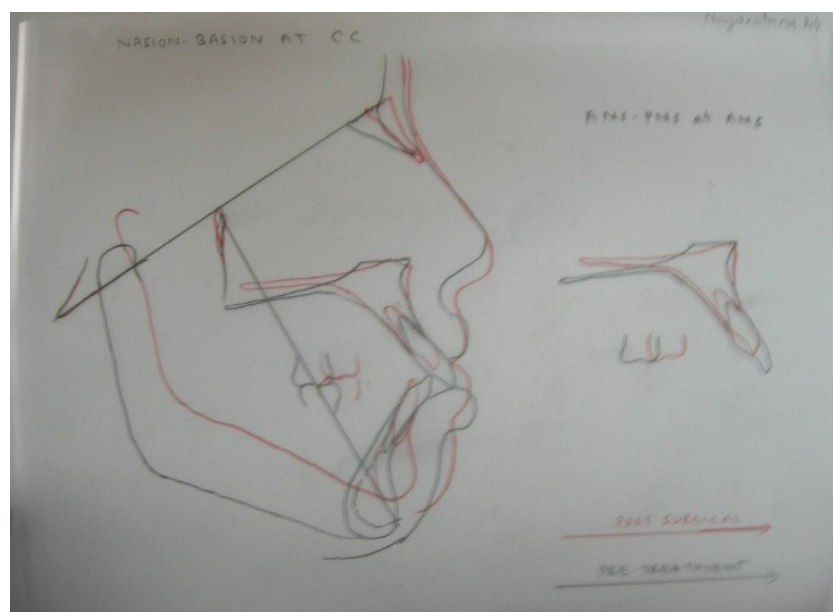

Fig 7: Superimposition of pretreatment (Green) and post treatment (Red) tracings

Table 1: Pretreatment and post-treatment cephalometric values

\begin{tabular}{|l|l|l|}
\hline & Pretreatment & Post Treatment \\
\hline Skeletal: & $83^{\circ}$ & $80^{\circ}$ \\
SNA & $77^{\circ}$ & $78^{\circ}$ \\
ANB & $6^{0}$ & $2^{\circ}$ \\
GoGn-SN & $30^{\circ}$ & $24^{\circ}$ \\
Y-Axis & $70^{\circ}$ & $65^{\circ}$ \\
& & \\
Dental: & $23^{\circ}, 11 \mathrm{~mm}$ & Dental: \\
U1-NA & $38^{\circ}, 16 \mathrm{~mm}$ & $20^{\circ}, 4 \mathrm{~mm}$ \\
L1-NB & $110^{\circ}$ & $32^{\circ}, 6 \mathrm{~mm}$ \\
U1-SN & $105^{\circ}$ & $107^{\circ}$ \\
IMPA & & $104^{\circ}$ \\
& & \\
Soft tissue: & $95^{\circ}$ & Soft tissue: \\
Nasolabial Angle & $43 \mathrm{~mm}$ & $109^{\circ}$ \\
Ar-ptm & $49 \mathrm{~mm}$ & $42 \mathrm{~mm}$ \\
Ptm-N & $48 \mathrm{~mm}$ & $48 \mathrm{~mm}$ \\
N-ANS & $79 \mathrm{~mm}$ & $51 \mathrm{~mm}$ \\
ANS-Gn & $53 \mathrm{~mm}$ & $68 \mathrm{~mm}$ \\
PNS-N & $26^{\circ}$ & $52 \mathrm{~mm}$ \\
MP-HP angle & $40^{\circ}$ & $20^{\circ}$ \\
1-NF & $50^{\circ}$ & $30^{\circ}$ \\
L1-MP & $57 \mathrm{~mm}$ & $46^{\circ}$ \\
Pns-Ans & $53 \mathrm{~mm}$ & $53 \mathrm{~mm}$ \\
Ar-Go & & $53 \mathrm{~mm}$ \\
\hline & & \\
\hline
\end{tabular}

\section{Discussion}

Two treatment plans were decided prior to beginning of Orthodontic treatment. Plan A was extraction of all first premolars and retraction of incisors followed by superior impaction of maxilla. The main drawback of this plan was thin alveolar trough, which makes it difficult in retracting the upper maxillary anterior teeth which led to the fenestration and dehiscence. Secondly the treatment duration was prolonged. Plan B was level align upper and lower arches and extraction of all first premolars during surgery which led to anterior alveolar segment setback in order to minimize orthodontic retraction of teeth over a large distance and reducing the treatment time.

Handelman, reported patients with either narrow alveolar width or severe skeletal discrepancies are most likely to demonstrate limitations in orthodontic correction and may require surgery. Thin alveolar widths were found both labial and lingual to the mandibular incisors in groups of high mandibular plane angle and lingual to the maxillary incisors in class II high angle groups. Orthodontic tooth movement in these patients results in iatrogenic loss of periodontal support. Considering the thin alveolar trough, it was decided to retract the maxillary anterior alveolar segment surgically rather than retracting the teeth over such a large distance.

Superior repositioning of the maxilla has proved to be a useful method for treating patients with vertical maxillary excess. The relationship of the upper lip line to the incisor is the keystone in planning treatment that will achieve an attractive smile. Superior repositioning of the maxilla leads to autorotation of the mandible with condyle as the centre of rotation. Wessberg et al reported that an occlusal programming feedback mechanism operated within the central nervous system mediating the compensatory autorotation of the mandible following surgical superior repositioning of the maxilla. Thus, in each instance when planning for surgical 
superior repositioning of maxilla one must decide on the basis of aesthetics and cephalometric prediction criteria, the magnitude of autorotation and the contribution of this rotation towards the desired occlusal and aesthetic results. In many instances a simultaneous mandibular surgery is not required to achieve the desired result. In this case, superior repositioning of the maxilla autorotated the mandible to achieve a good facial profile resulting in no need for any additional mandibular surgery like mandibular advancement or genioplasty.

In treating a patient surgically the stability of the surgical procedure is essential. With rigid fixation, the maxilla is quite stable during the first postsurgical year when moved up and there is almost no chance of clinically significant change. Superior repositioning of the maxilla falls into the highly stable category of surgery. Also, soft tissue changes noted 1 year following surgery is likely to remain stable for the next 5 years.

\section{Conclusion}

This case report highlights the importance of careful diagnosis and appropriate treatment planning so that the problem is identified and treated accordingly. The aesthetic improvement achieved with this approach is high and requires good coordination between the orthodontist and the maxillofacial surgeon.

\section{References}

[1]. Schendel SA, Einsenfeld J, Bell WH, Epker BN, Mishelevich DJ. The Long face syndrome: vertical maxillary excess. AM J Orthod 1976;70(4):398-408

[2]. Radney LJ, Jacobs JD. Soft tissue changes associated with surgical total maxillary intrusion. AM J Orthod 1981;80(2):191 -212

[3]. Fish LC, Wolford LM, Epker BN. Surgical-orthodontic correction of vertical maxillary excess. Am J Orthod 1979;73(3):241-257

[4]. Bell WH, Dann JJ. Correction of dentofacial deformities by soft-tissue changes. Am J Orthod 1973;64(2):162-187

[5]. Wessberg GA, Washburn MC, Labanc JP, Epker BN. Autorotation of themandible: effect of surgical superior repositioning of the maxilla on mandibular resting posture. Am J Orthod 1982;81(6):465-472

[6]. Sarver DM, Weissman SM. Long-term soft tissue response to Lefort I maxillary superior repositioning. Angle Orthod 1991;61(4):267-276

[7]. Bell WH, Creekmore TD, Alexander RG. Surgical correction of the long face syndrome. Am J Orthod 1977;71(1):40-67

[8]. Handelman CS. The anterior alveolus: its importance in limiting orthodontic treatment and its influence on the occurrence of iatrogenic sequelae. Angle Orthod 1996;66(2):95-110

[9]. Lew KK. Orthodontic considerations in the treatment of bimaxillary protrusion with anterior subapical osteotomy. Int J Adult OrthodonSurg 1991;6(2):113-122

[10]. Kent JN, Hinds E. Management of dental deformities by anterior alveolar surgery. J Oral Surg 1971;29(1):13-26

[11]. Reyneke JP. Essentials of Orthognathic surgery, China 2003, Quintessence publishing co.

[12]. Bell WH, Jacobs JD, Legan HL. Treatment of class II deep bite by orthodontic and surgical means. Am J Orthod Dentofacial Orthop 1984;85:1-20

[13]. Profit WR, fields HW, Sarver DM. Contemporary Orthodontics. (4 ${ }^{\text {th }}$ ed). St. Louis, 2007, Elsecier. 